
$\stackrel{-}{-}$

\section{Staving off extinction - more than luck and fate}

Adrian Burton regularly writes a fascinating column in Frontiers, and his article from December 2016 ("Staving off extinction") discusses two Australian species: the Bramble Cay melomys (Melomys rubicola) and the Lord Howe Island stick insect (Dryococelus australis). However, we suggest the article misses a key and generalizable point about their fates (extinction and to-date successful conservation, respectively) as well as the factors that led to those fates. That is, the Lord Howe Island stick insect survives today not simply because of luck but because conservation managers intervened rapidly, effectively, and decisively (Priddel et al. 2003). Consequently, there are now captive colonies around the world and staged plans for an eventual reintroduction to Lord Howe Island (Priddel and Carlile 2010). Although its future in the wild is not yet secured, the stick insect is a remarkable story of conservation success. Conversely, the Bramble Cay melomys was rendered extinct in large part because of management inaction and disregard. As Burton noted, this was a species living on a knife-edge: it should have been evident to any person or agency with any responsibility for its survival that it needed help. Its extinction could readily have been averted - and should have been - through simple and appropriate conservation actions (Woinarski et al. 2017).

Many species are now on the edge of oblivion (Maxwell et al. 2016). In response, international policy such as the Aichi Biodiversity Targets and the UN's Sustainable Development Goals explicitly commit governments to "prevent the extinction of threatened species". What can these two case studies tell us about the mismatch between this clear policy commitment and its realization? Obviously, they suggest that the fate of such species will increasingly depend upon whether (and how) managers and the community respond to imperilment.
From these two cases, we recognize four factors that may influence the degree of management response:

(1) The risk of imminent extinction needs to be explicitly assessed and that risk then used to prioritize management response. There are many appropriate risk assessment procedures, such as Population Viability Analysis and IUCN Red List assessment. In these two cases, no numerical assessment of extinction risk was undertaken. But in a less formalized process for the stick insect, several factors led managers to appreciate the species' proximity to extinction: it had disappeared from all of its previously known range, a well-defined threat (introduced predators) still operated, and its newly discovered population comprised only a handful of individuals. Managers were more complacent about risks to the Bramble Cay melomys, because it had long persisted in its (very small) range and the limited monitoring data indicated only gradual decline. Nevertheless, the low-lying island on which it occurred was at risk of inundation. Its susceptibility to catastrophic habitat loss and hence high extinction risk should have prompted policy and management response, but sadly did not.

(2) Effective advocacy is critical; politicians, policy makers, resource managers, and human societies per se are more likely to respond if a species has a public profile and therefore a broad constituency pushing for its conservation. The stick insect's range happened to lie within a conservation reserve staffed by committed conservation officers, and its quirky rediscovery by extreme adventurers climbing an isolated oceanic rock spire prompted media attention and fostered interest and diverse community support from schoolchildren to politicians. The Bramble Cay melomys, on the other hand, had no champions. It lived on a small, remote, and uninhabited island visited by few people; even researchers paid it scant attention. In contrast to the normal order of things, in this case, the invertebrate had charisma whereas the mammal was a "lackluster" rodent. We suggest there is a need to raise the public profile of species more in line with extinction risk and ensure that any need for emergency response (without which extinction will almost certainly occur) is widely communicated to a broad constituency within society. However, this is a complex issue because many conservationists have long used charismatic species (sometimes with relatively low extinction risk) to attract public interest and to rightly build the support needed to influence policy makers.

(3) Managers are more likely to invest in a conservation response if there is a strategic, detailed, and objectives-based

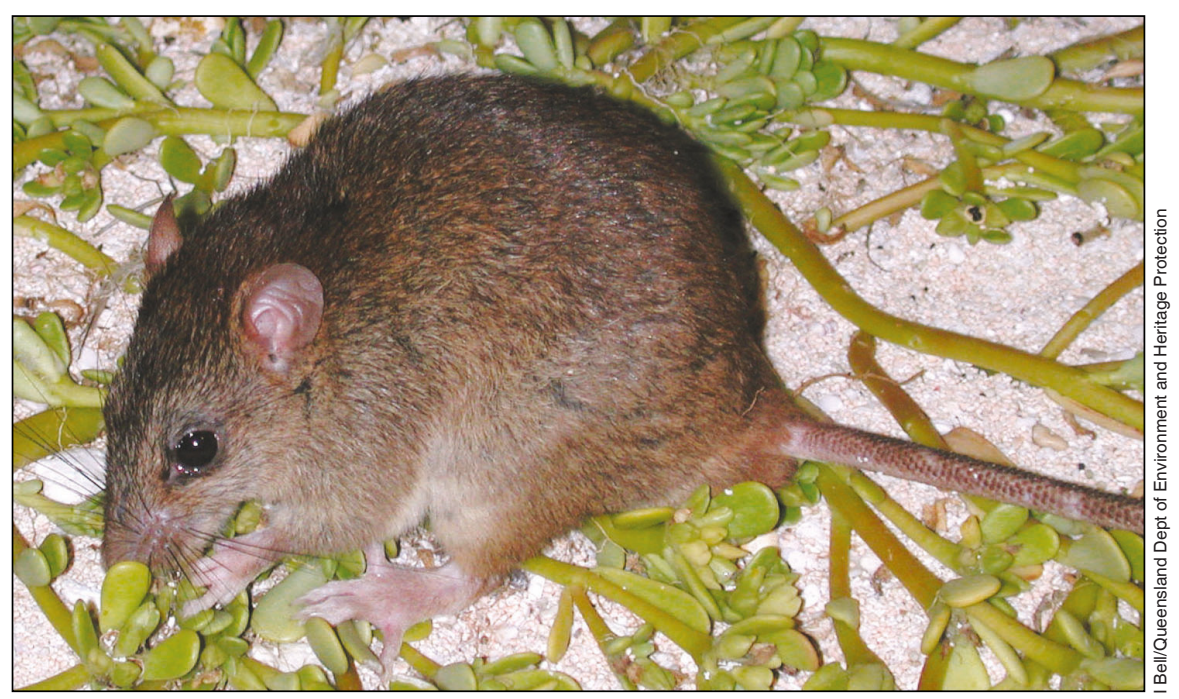

Figure 1. The Bramble Cay melomys (Melomys rubicola) was lost because nobody intervened to save it. 
process or plan for recovery with well-articulated priorities for action and a clearly justified budget. In the case of the stick insect, the recovery pathway - captive breeding, threat reduction, and reintroduction - was clear and practical. The recovery plan prepared for the Bramble Cay melomys provided a comparatively opaque and insufficient pathway to recovery.

(4) As per international goals, governments should strive to prevent all avoidable extinctions. To allow through neglect, ineptitude, community disinterest, or deliberate choice - "saveable" species to become extinct is to abrogate responsibility and to open a door to ever-increasing disregard for extinctions. We recognize that this objective will be challenging to meet but not to do so is likely to result in more cases of avoidable extinction. Of course, government commitments alone do not ensure action or success. Commitments need to be more firmly based in law and implemented effectively through organizational processes (Woinarski et al. 2017).

Conservation biology needs fewer failures and more success stories to engender greater support from the general public about the importance of the science and management of preserving biodiversity (Garnett and Lindenmayer 2011). The contrast between the stories of failure for the Bramble Cay melomys and of success for the Lord Howe Island stick insect is stark and illustrates the difference that informed action can make.

\section{David B Lindenmayer ${ }^{1 *}$, John CZ}

Woinarski ${ }^{2}$, Sarah M Legge ${ }^{1}$, and Stephen T Garnett ${ }^{2}$

${ }^{1}$ National Environmental Science Programme Threatened Species Recovery Hub, Fenner School of Environment and Society, The Australian National University, Canberra, Australia *(david.lindenmayer@anu.edu.au);

${ }^{2}$ National Environmental Science

Programme Threatened Species Recovery

Hub, Charles Darwin University,

Casuarina, Australia
Garnett ST and Lindenmayer DB. 2011. Conservation science must engender hope to succeed. Trends Ecol Evol 26: 59-60.

Maxwell S, Fuller RA, Brooks T, and Watson J. 2016. Biodiversity: the ravages of guns, nets and bulldozers. Nature 536: 143-45.

Priddel D and Carlile N. 2010. Return of the Lord Howe Island phasmid to Lord Howe Island, Australia. In: Soorae PS (Ed). Global re-introduction perspectives: additional case-studies from around the globe. Abu Dhabi, UAE: IUCN/SSC Re-introduction Specialist Group.

Priddel D, Carlile N, Humphrey M, et al. 2003. Rediscovery of the extinct Lord Howe Island stick-insect (Dryococelus australis [Montrouzier]) (Phasmatodea) and recommendations for its conservation. Biodivers Conserv 12: 1391403.

Woinarski JCZ, Garnett ST, Legge SM, and Lindenmayer DB. 2017. The contribution of policy, law, management, research and advocacy failings to the recent extinctions of three Australian vertebrate species. Conserv Biol 31: 13-23.

\section{Executive Director Washington, DC}

doi:10.1002/fee.1533

The Ecological Society of America (ESA) - the largest community of professional ecologists in the world invites nominations and applications for the position of Executive Director. Following more than two decades of dedicated leadership from outgoing Executive Director, Katherine McCarter, ESA is poised to enter a new era of service to its members and to society. With 9,000 members globally, ESA is the flagship organization for one of the youngest, most energetic scientific fields today, with an extremely broad disciplinary scope and important policy relevance. The Society connects scientists across multi-faceted disciplines and promotes ecological science through high-quality publications, events, and educational programs. It works to infuse ecological knowledge into national dialogue and to garner federal support for ecological research.

The Executive Director oversees a staff of 26 and an operating budget of $\$ 5.4$ million. The position calls for a dynamic leader and spokesperson who brings proven managerial and organizational leadership skills and outstanding abilities in communication, collaboration, and customer service. While scientific credentials and/ or professional experience in ecology would be an asset, ESA is open to strong candidates from a range of professional backgrounds. Informed passion for ecology and the role of science in society is essential.

An eight-member search committee has been established to conduct this search on behalf of ESA's Governing Board. The search committee is assisted by Isaacson, Miller, Inc., a national executive search firm.

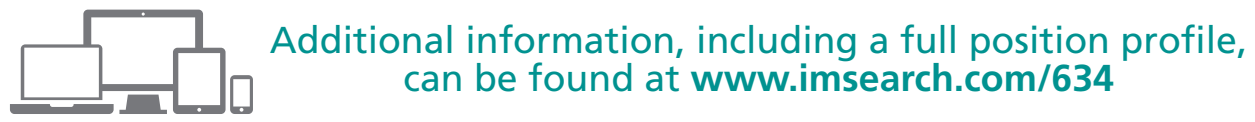

The Ecological Society of America is an Equal Opportunity Employer. We seek and welcome a diverse pool of candidates in this search. Applications received by November 1, 2017, will be assured full consideration. 